\title{
MEMORIA VECINAL Y CONSTRUCCIÓN BARRIAL. EL CASO DEL BARRIO “PREFECTURA” DE LA CIUDAD DE CORRIENTES*
}

\author{
Neighborhood memory and neighborhood construction. \\ The case of the "Prefectura" neighborhood of the city of Corrientes
}

Miguel Ángel Riera**

\section{Resumen}

En la década del 60 del siglo XX se implementó en la Argentina el Plan Federal de la Vivienda, contemplando la construcción de barrios como producto de un préstamo efectivizado por el Banco Interamericano de Desarrollo. En la ciudad de Corrientes, a mediados de la misma se habilitó el sector denominado "barrio Prefectura", formando parte en la actualidad del barrio Cambá Cuá, conformando 36 viviendas individuales ocupadas por personal perteneciente a la actual Prefectura Naval Argentina. Los residentes iniciales recuerdan las características de ese sector de la ciudad que por entonces manifestaba una imagen periférica por la carencia parcial de infraestructura y con numerosos espacios baldíos. El objetivo de este trabajo es dar a conocer el ejercicio de la memoria llevado adelante por vecinos de un sector de viviendas sociales del barrio objeto de estudio en la ciudad de Corrientes, testigos de los cambios que se sucedieron en un sector del espacio urbano a lo largo de cinco décadas.

$$
<\text { Memoria vecinal }><\text { Construcción barrial }><\text { Barrio Prefectura }><\text { ciudad de Corrientes }>
$$

\begin{abstract}
In the 60 s of the 20th century, the Plan Federal de la vivienda was implemented in Argentina. It contemplated the construction of neighborhoods as a result of a loan by the Banco Interamericano de Desarrollo. In the city of Corrientes, in the middle of that decade, the sector called "Barrio Prefectura", currently part of the Cambá Cuá neighborhood, was created. It was composed by 36 individual dwellings occupied by personnel belonging to the current Prefectura Naval Argentina. The initial residents remember the characteristics of that sector of the city. At that time, it manifested a peripheral image due to the partial lack of infrastructure and numerous empty spaces. The objective of this work is to show the memory exercise made by neighbors of a social housing sector of the neighborhood under study in the city of Corrientes. They were witnesses of the changes that took place in a sector of the urban space during five decades.
\end{abstract}

$<$ Neighborhood report $><$ Neighborhood construction $><$ Prefectura neighborhood $><$ Corrientes city $>$

Recibido: 10/11/2017 // Aceptado: 20/12/2017

* El autor agradece a la Sra. Mercedes Mancera de Silva y al Sr. Eduardo Rial Seijó.

** Arquitecto FAU UNNE. Especialista en Docencia Universitaria. FH UNNE. Profesor Adjunto a cargo de la asignatura Historia del Diseño Gráfico I, FAU UNNE. Jefe de Trabajos Prácticos de la asignatura Historia y Crítica de la Arquitectura III, FAU UNNE. Investigador en el Centro de Investigación en Arquitectura Moderna CIAM. miguelangelriera@yahoo.com.ar; arqmiguelriera@gmail.com 
Riera. Memoria vecinal y construcción barrial. El caso del barrio "Prefectura" de la ciudad de Corrientes.

\section{Introducción}

El Estado Argentino asumió la problemática de la vivienda de interés social en las primeras décadas del siglo XX, debido al proceso de urbanización producto de la inmigración poblacional procedente del espacio europeo, del espacio nacional y de los países limítrofes. El Banco Hipotecario Nacional asumió un rol significativo en el financiamiento de obras destinadas a la vivienda social, conjuntamente con organizaciones de tipo cooperativistas y aquellas vinculadas a la Iglesia Católica.

El gobierno peronista instaurado en el país entre 1946 y 1955, dentro de un importante plan de obras públicas posicionó a la construcción de viviendas de interés social en un lugar relevante, potenciado por la modificación de la carta orgánica del Banco Hipotecario Nacional que lo ubicó como órgano centralizador en la construcción de barrios que adoptaron la modalidad de vivienda individual y colectiva.

La caída del peronismo en 1955 produjo cambios en el manejo operativo de la entidad crediticia aunque manteniendo un rol protagónico en la política financiera vinculada a la vivienda social. La entidad bancaria llevó adelante sus propios programas de construcción, incorporados dentro del mecanismo de ahorro y préstamo, del cual podían participar solamente sectores sociales de ingresos medios y superiores, además de entidades intermedias.

En la ciudad de Corrientes, en la década del 60, se concretó la construcción de diversos barrios de viviendas individuales bajo esta normativa, entre ellos el denominado "barrio Prefectura", que ocupó un sector en aquel entonces con déficit de infraestructura urbana, baja ocupación del suelo pero próximo al centro comercial y a la Avenida Costanera "General San Martín", posicionada como el principal paseo recreativo de la ciudad.

Organizado en aspectos que contemplan la vivienda social en la planificación del Estado Nacional, la memoria ciudadana en el "barrio Prefectura" y la conclusión, el presente trabajo tiende a destacar la manera en que los vecinos de un barrio de viviendas de interés social de la ciudad de Corrientes, a través del ejercicio de la memoria, testimonian los cambios producidos en un sector urbano a lo largo de medio siglo.

\section{La vivienda social en la planificación del Estado Nacional}

La vivienda de interés social es entendida como "Habitación de bajo costo, destinada a sectores sociales medios y bajos, que a partir de la década de 1940 se encuentra asociada a la acción del Estado" (Aliata - Liernur, 2004: 176). Desde la dimensión histórica, podemos señalar que la cuestión del tema de la vivienda y el alojamiento popular es referida como problema económico y social propio de las sociedades modernas. Inicialmente asociado a los sectores obreros, hacia mediados del siglo XX también es destacada como problemática que afectó a los sectores medios conformados por empleados públicos y pequeños comerciantes. La inmigración proveniente del espacio rural, de países limítrofes como así también la de ultramar promovida por el Estado tuvo directa relación con la condiciones de habitabilidad de una importante franja poblacional. "El abrupto arribo de estos extranjeros sumado a 
la inmigración de los criollos expulsados de la tierra, modificó el panorama laboral en las ciudades, las cuales se poblaron de obreros ligados a la alimentación, el vestido o el transporte" (Bontempo, 2010: 25). Ello generó la aparición de espacios inadecuados para la residencia en condiciones de hacinamiento que atentaron contra la salubridad y la higiene, generando conflictos sociales devenidos de las inadecuadas condiciones de convivencia, dando origen al conventillo, "Concebido como una serie de cuartos de alquiler alrededor de un patio central, éstas viviendas colectivas solían ser adaptaciones de antiguas residencias de la élite, así como nuevas construcciones de precaria calidad y un óptimo aprovechamiento del terreno"(Bontempo, 2010: 25).

La "Comisión Nacional de Casas Baratas" abordó durante las primeras décadas del siglo XX la situación imperante en la población de bajos recursos, destinando sus acciones a la mejora de la calidad de vida en el espacio doméstico. "El hecho más importante del periodo, la creación de la Comisión Nacional de Casas Baratas -Ley 9677 de 1915- se debió a la iniciativa del diputado católico por la Provincia de Córdoba Juan Félix Cafferata, quien proponía el tema en el Congreso desde 1912” (Aliata y Liernur, 2004: 177).

El Banco Hipotecario Nacional, fundado en 1886, a partir de 1919 tuvo asignado el otorgamiento de préstamos a empleados públicos, destinados a la construcción o adquisición de vivienda propia, casi en simultáneo con las acciones emprendidas por la grupos socialistas y católicos. "El primero de ellos devino del partido Socialista: la Cooperativa El hogar obrero. Creada en vísperas de la huelga de inquilinos por médicos hijos del higienismo, la cooperativa centraría su acción en el otorgamiento de créditos y la construcción en terrenos de la periferia urbana...El otro sector fue el eclesiástico que se propuso salvar al obrero del influyente comunismo soviético, promoviendo una sociedad ordenada de familias propietarias "'(Bontempo, 2010: 49).

El gobierno peronista instaurado en el país entre 1946 y 1955, dentro de un importante plan de obras públicas posicionó a la construcción de vivienda de interés social en un lugar relevante, potenciado por la modificación de la carta orgánica del Banco Hipotecario Nacional que lo ubicó como entidad crediticia centralizadora en la construcción de barrios, los cuales se materializaron por un lado bajo el criterio de la vivienda individual, focalizado en la familia como componente básico de la sociedad y por el otro el de la colectiva, acentuado en la socialización ciudadana al compartir espacios comunes de un conjunto barrial. "En forma inédita hasta esta época, la acción del Estado tuvo un claro carácter federal interviniendo en lugares otrora olvidados" (Bontempo, 2010: 91). Con la caída de este gobierno en 1955, el Banco Hipotecario continuó centralizando la política financiera en lo concerniente a la vivienda social pero respondiendo a una concepción diferente al período anterior.

En 1957 se realizó la reorganización bancaria lo que produjo también la sanción de la nueva carta orgánica, reglamentada en 1958. La entidad crediticia llevó adelante sus propios programas de construcción, incorporados dentro del mecanismo de ahorro y préstamo, del cual podían participar solamente sectores sociales de ingresos medios y superiores. "En 1962 el Banco Interamericano de Desarrollo concedió un préstamo de 30 millones de dólares destinado a cubrir el $50 \%$ del costo total de un programa de 
Riera. Memoria vecinal y construcción barrial. El caso del barrio "Prefectura" de la ciudad de Corrientes.

viviendas, que se efectivizaría con el nombre de Plan Federal de la Vivienda y se aplicaría a través del BHN. Se produjo así, a partir del crédito externo, una nueva concentración de funciones en el Banco Hipotecario Nacional" (Aliata y Liernur, 2004: 125).

Las entidades intermedias tuvieron participación, dentro de las cuales se encontraban Instituciones vinculadas a gremios laborales o cooperativas de vivienda, organismos de viviendas dependientes de gobiernos provinciales o municipales, empresas privadas, fuerzas armadas, instituciones destinadas a esfuerzo propio y ayuda mutua como así también los organismos destinados a la erradicación de villas de emergencia. "Los flujos de los fondos externos se sintieron durante el gobierno radical del doctor Arturo Illia (1963-1966) cuando se pusieron en marcha los programas basados en ellos" (Ballent, Liernur, 2014: 293).La efectiva aplicación de este sistema tuvo su concreción particular en las principales ciudades del país, como así también en las capitales provinciales, ocupando sectores intermedios y periféricos en virtud de la disponibilidad de suelo urbano que en su gran mayoría, no contó con infraestructura completa.

\section{Memoria ciudadana en el "barrio Prefectura"}

En la ciudad de Corrientes, los primeros barrios de viviendas de interés social llevados adelante por el Estado fueron el "Perón" (actual "Yapeyú") y "Evita" (actual "Berón de Astrada"), construidos entre 1949 y 1951. El criterio de vivienda individual fue materializado en estos dos conjuntos barriales, caracterizados por la definición en el trazado urbano de espacios verdes, como así también la incorporación de especies vegetales en sus calles. Hacia 1960, la ciudad contaba con 97.507 habitantes conforme al Censo Nacional de Población llevado adelante ese año. La misma ofrecía un paisaje arquitectónico caracterizado por la densificación edilicia en el sector central próximo al puerto, con una escala constructiva predominantemente baja al no superar los dos niveles, destacándose como construcciones más elevadas en el perfil urbano las torres de las iglesias, conjuntamente con dos edificios construidos y habilitados en la década anterior: el Correo (1957) y la Lotería Correntina (1958). El trazado en damero caracterizaba el sector urbano mayormente consolidado que en ese entonces estaba delimitado al norte y oeste por la avenida costanera General San Martín como borde costero del río Paraná, al sur por las avenidas 3 de abril y Pedro Ferre, al este por las avenidas Poncho Verde y Artigas. La infraestructura de energía eléctrica, agua corriente, desagües cloacales y pluviales, al igual que pavimento se extendía en gran parte de las calles. Más allá de los límites anteriormente enunciados, la ciudad ofrecía un paisaje caracterizado por superficies de baja densidad constructiva, predominando los baldíos y construcciones de perímetro libre. Los sectores próximos a la avenida Poncho Verde, Artigas y costanera General San Martín definían déficit de infraestructura en lo concerniente a desagües cloacales y pluviales como pavimento, sumado a la existencia de superficies baldías en parte de sus manzanas.

Una obra significativa en los inicios del siglo XX, fue la intervención en el borde costero, lo cual definió una nueva imagen que caracteriza hasta el presente a la ciudad. “...la ribera del Paraná se urbanizó y embelleció con la construcción de la 
avenida costanera...y más tarde con la edificación del barrio residencial que hoy la bordea..." (Gutiérrez y Maeder, 2003: 46). En virtud de que el tejido urbano había avanzado hasta prácticamente la línea de ribera y luego de haberse concretado un largo proceso de expropiaciones para la liberación de la traza con vistas a la construcción de la avenida costera, las obras se llevaron adelante de manera efectiva a partir de 1929 y hasta 1951 en el tramo comprendido entre el acceso al parque Mitre y la avenida 3 de abril, definiendo un espacio recreativo distintivo en la ciudad, posibilitando además de un alternativa de circulación vial, el saneamiento de sectores urbanos ribereños, particularmente localizados en el sector oeste del área central.

El mismo lo constituía un sector del barrio "Cambá Cuá", lugar de la ciudad que en el pasado albergó a población de piel oscura que prestó servicios domésticos a las familias pudientes, identificada en guaraní como "Kamba: personal de piel oscura, negro - a quemado - a al sol"'(Moliniers y Genes, 1997: 35),"Kua: s. agujero, hueco, orificio" (Moliniers y Genes, 1997: 39) recibiendo esa denominación en virtud de ello, entendida como "lugar de negros". Concretamente, lo conformaba un "grupo humano que en su mayoría trabajaba en casa de familias tradicionales de la ciudad, ("los amitos"), a los que se consideraban comadres o compadres, por haber alzado a sus hijos en la pila bautismal" (Salas, 1990: 15). El sector comprendido por las calles Junín al norte, av. 3 de abril al sur, Juan Pujol (actual Chaco) al este y avenida costanera General San Martín al oeste, carecía de redes cloacales, pluviales y pavimento. Equipamientos como el anfiteatro “José Hernández”, Instituto Pío XI, la usina termoeléctrica, la planta de abastecimiento de combustible de Yacimientos Petrolíferos Fiscales YPF, el Regimiento 9 de Infantería, la Cárcel Penitenciaria, la estación terminal del Ferrocarril General Urquiza, la delegación local de la Dirección Nacional de Vialidad, el entonces Hotel Nacional de Turismo, pueden destacarse en ese momento en sus proximidades. A mediados de los sesenta, en las manzanas 173 A y 173 B, se construyó el denominado "barrio Prefectura", por cuanto los residentes iniciales lo conformaron personal de dicha institución. Estos terrenos se localizan en proximidades de la avenida costanera, delimitado por las calles Pago Largo al este, Don Bosco al oeste, parcelas linderas con la calle Junín al norte y la calle Yrigoyen al sur, conformando 36 viviendas de dos y tres dormitorios.

Podemos entender a la Memoria como "facultad psíquica por medio de la cual se retiene y recuerda el pasado" (http://dle.rae.es/?id=OrlyaVdwww.rae.es). Los vecinos residentes en el sector de estudio, reflexionaron a través de la memoria respecto a tiempos pasados posicionando su relato desde los momentos iniciales de concreción y efectiva ocupación de las viviendas hasta el momento presente. "Toda persona que recuerda domestica el pasado pero, sobre todo, se apropia de él, lo incorpora y lo marca con su impronta, etiqueta de memoria manifiesta en los relatos o memorias de vida" (Candau, 2002: 117). Con ello el recuerdo vivido expresado remite a la historia de vida que permite conocer la manera en que el tiempo definió cambios en el sector en estudio, mediante transformaciones edilicias, advenimiento de mejoras urbanas, vivencias de la comunidad. "Un acto de memoria es ante todo esto: una aventura personal o colectiva que consiste en ir a descubrirse uno mismo gracias a la retrospección”" (Candau, 2002:123). 
Riera. Memoria vecinal y construcción barrial. El caso del barrio "Prefectura" de la ciudad de Corrientes.

Los vecinos iniciales de este grupo barrial, recuerdan como era el sector en ese entonces:

Vecino 1. El terreno de este barrio era propiedad de la Iglesia, más precisamente de la parroquia de La Merced que tenía proyectado hacer una capilla en este sector. La calle cortada que se encuentra en este sector se denomina "La Merced" justamente por esa cuestión.

Vecino 2. Antes de construirse el barrio, esto era un gran baldio usado como cancha de fútbol.

Respecto al origen del conjunto, señalaron:

Vecino 1. Los construyó la Prefectura para su personal, como mi esposo trabajaba alli, pudo acceder a esta vivienda. Vine a vivir en 1965. Pagábamos mensualmente las cuotas que en general eran accesibles.

Vecino 2. El barrio estaba destinado al personal de la prefectura, el pago lo hacíamos mensualmente en el Banco Hipotecario.

El entorno barrial también es descripto por los usuarios iniciales, señalando algunas particularidades respecto a las condiciones de las calles.

Vecino 1. Cuando me mude al barrio no teníamos cloaca ni pavimento, éste llegaba hasta la calle Junín y la calle Chaco, que en ese entonces se llamaba Pujol. Había baldios sobre la calle Yrigoyen y la calle Borgatti, antes llamada Cerrito, cerca del Pío.

Vecino 2. El barrio no era lo que es hoy en día, cambió mucho. Antes no teníamos pavimento y los dias de lluvia era complicado entrar y salir de la casa porque las calles estaban en mal estado. Por lo menos el pavimento no estaba muy lejos. Había muchos baldios alrededor que con el tiempo se fueron ocupando.

Respecto a los servicios urbanos destacan:

Vecino 1. El barrio estaba bien servido por colectivos, teníamos dos líneas sobre la costanera, la 2 y 3 , eran las que nos quedaban más cerca. La otra línea era la 10 que nos quedaba un poco más lejos, pero igual no a mucha distancia. Las calles eran de tierra y se mantenían muy poco, la maquina pasaba muy de vez en cuando, además de poco alumbrado.

Vecino 2. El centro parecía lejos pero no lo era tanto, por los baldios y las calles de tierra esto parecía estar en la periferia. Teníamos colectivos en la costanera, además en aquél entonces teníamos trenes y la estación nos quedaba cerca porque estaba frente al Regimiento, a unas seis o siete cuadras de aquí. Recuerdo los yuyales en los baldios y las 
cunetas que no se mantenían mucho, igual que las calles de tierra. En general este sector era limpio, seguramente porque no éramos muchos habitantes.

Los equipamientos próximos son destacados por su convocatoria en el sector:

Vecino 1. En aquel tiempo lo más cercano era el anfiteatro "José Hernández" que es un escenario sobre la costanera, después ya estaban el colegio Pio XI de los Salesianos, la escuela $N^{o} 10$, algunos almacenes, pasaba el verdulero en carro y después en camioneta. El centro está cerca y no tuvimos mayores problemas para hacer las compras.

Vecino 2. Los comercios cercanos eran los almacenes que estaban en las casas del barrio cuando llegué, eran pocos y en aquellos tiempos el supermercado como hoy se lo conoce no había. Escuelas cercanas teníamos en el colegio salesiano Pio XI, la escuela $N^{\circ} 10$ que estuvo primero en una antigua casona en Bolivar y Misiones y después se trasladó al barrio Ferré cuando a éste lo habilitaron. Hospitales o sanatorios cercanos no teníamos, salvo una sala de primeros auxilios en el barrio Ferré, hoy llamado centro asistencial Sussini. La estación de trenes, la cárcel y el regimiento lo teníamos cerca, además de la usina eléctrica sobre la costanera, recuerdo que por la noche sentíamos el ruido de los equipos de luz.

Espacios públicos convocantes dentro del conjunto barrial no existían y como espacio de socialización definen a la cercana avenida costanera:

Vecino 1. Como el barrio es chico, no tenemos plaza y el espacio de encuentro es la costanera que nos queda a un paso. Otro lugar de encuentro pienso que es la Parroquia de María Auxiliadora del Colegio Salesiano Pío XI. Cuando se hacían espectáculos musicales en el anfiteatro, nos encontrábamos con algunos vecinos aunque generalmente eran espectáculos a los que venía gente de otros barrios.

Vecino 2. No había dentro del barrio un lugar tipo plaza, nos conocíamos la mayoría de los vecinos porque al comienzo éramos todos empleados de la Prefectura y además son pocas casas. Me acuerdo que en la época de verano la gente se sentaba en las veredas, cenaba alli y hasta he visto gente durmiendo en catre. Era otra época, hoy eso es imposible por la inseguridad general.

La calidad constructiva de las viviendas es señalada como muy buena:

Vecino 1. Las casas son de buena calidad, nos entregaron con la cocina amueblada y las instalaciones de agua y luz. No tuvimos mayores problemas salvo en el techo de tejas que queda muy lindo pero cuesta 
Riera. Memoria vecinal y construcción barrial. El caso del barrio "Prefectura" de la ciudad de Corrientes.

mantenerlo porque no se consigue buena mano de obra para el arreglo y si conseguís, te cobran caro.

Vecino 2. No me puedo quejar de la casa, es cómoda, funcional, linda. La construyeron bien y salvo alguna que otra gotera, el resto no tuvo problemas. Nos entregaron hasta con el mueble de cocina y con piso de parquet en el comedor y los dormitorios.

Los cambios que se dieron en el barrio desde su habilitación hasta el presente son señalados de la siguiente manera:

Vecino 1. El barrio cambió mucho. La mayoría de las casas fueron modificadas y pocas quedan como estaban al comienzo. Hay familias que vendieron su casa y los que la compraron la modificaron. Este sector de la ciudad cambió mucho, los baldios desparecieron y se construyeron y construyen varias torres. Cuando las calles se pavimentaron a fines de los setenta, el barrio cambió más rápido, se puso más lindo. Las propiedades se valorizaron más, comprar hoy una casa en esta zona sale muy caro.

Vecino 2. El barrio está muy cambiado. Cuando me vine a vivir acá con mi familia era como estar en la periferia, y eso que el centro no está lejos. Hoy es distinto, esto se volvió residencial, tenemos casas ampliadas dentro de nuestro grupo pero sobre todo en los alrededores se construyeron algunas torres de departamentos. Algunos vecinos se fueron, otras fallecieron y quedaron sus hijos, en general nos seguimos relacionando pero ahora hay más gente en los alrededores. Cambió para mejor, en general el barrio es tranquilo aunque no como antes, ahora hay que cuidarse más.

Conforme al relato de los informantes clave, el sector en estudio presentó en los tiempos iniciales de ocupación de las viviendas, características propias de un área periférica de la ciudad, ubicado a poca distancia del centro. La identificación inicial del sector respondió a la iniciativa del organismo de seguridad que lo llevó adelante, inserto en las políticas públicas implementadas por el gobierno nacional, generando en la comunidad un marcado sentido de pertenencia en los primeros momentos de ocupación. El sector no fue provisto de equipamiento de apoyo, por lo cual el existente previamente en el sector, fue utilizado por la comunidad vecinal. La calidad constructiva, el servicio de transporte urbano son destacados como favorables mientras que la carencia de infraestructura vial es señalada como una debilidad inicial del conjunto. El paso del tiempo con los cambios propios del sector urbano, dado por la modificación de algunas viviendas por lógicas transformaciones en función del aumento y/o modificación del grupo familiar, además del crecimiento edilicio "vertical" que presenta el entorno inmediato, son aspectos señalados como positivos. 


\section{Conclusión}

La memoria vecinal manifiesta el paso del tiempo de acuerdo a sus vivencias en el sector barrial, testimoniando el paso de los años que evidencian al presente modificaciones en la estructura física de un sector de la ciudad. Conformado por viviendas que albergaron inicialmente a familias del personal dependiente de la Prefectura Naval Argentina, al momento de su concreción se localizaba en la periferia urbana y con el paso del tiempo, la consolidación del sector con el advenimiento de la infraestructura urbana carente en tiempos iniciales, sumado a los cambios lógicos en las viviendas y la importante inversión inmobiliaria que el entorno inmediato detenta al presente, definen las características de un sector de la ciudad en el recuerdo vecinal, rescatando vivencias en comunidad.

Al presente, el inicialmente denominado "barrio Prefectura", se inserta en un sector de la ciudad con dinámica edilicia singular, manteniendo en líneas generales las características arquitectónicas iniciales más allá de casos puntuales de transformación absoluta.

\section{Referencias bibliográficas}

Aliata, F. y Liernur, J. (2004). Diccionario de arquitectura en la Argentina. Tomos A-B, $S-Z$. Buenos Aires: Clarín arquitectura.

Ballent, A. y Liernur, J. (2014). La casa y la multitud. Vivienda, política y cultura en la Argentina moderna. Buenos Aires: Fondo de Cultura Económica de Argentina S.A. Bontempo, L. (2010). Umbrales de un siglo. Una historia de la vivienda social en la Argentina. De los conventillos al Plan Federal. Buenos Aires: Ministerio de Planificación Federal, Inversión Pública y Servicios.

Candau, J. (2002). Antropología de la memoria. Buenos Aires: Ediciones Nueva Visión. Gutiérrez, R. y Maeder, E. (2003). Atlas del Desarrollo Urbano del Nordeste Argentino. Resistencia: Instituto de Investigaciones Geohistóricas, CONICET.

Moliniers, P. y Genes, I. (1997). Diccionario Guaraní. Buenos Aires: Visor Enciclopedias Audiovisuales S.A.

Salas, A. (1990). Loscambá, el camba cuá y cambaltazar. De los negros y sus tradiciones en la provincia de Corrientes. Corrientes: Editorial Aguaradas.

\section{Fuentes}

Censo Nacional de Población, año 1960.

Real Academia Española. www.rae.es 
Riera. Memoria vecinal y construcción barrial. El caso del barrio "Prefectura" de la ciudad de Corrientes.

\section{Apéndice}

Figura 1. Plano de la ciudad de Corrientes de fines de la década del 60

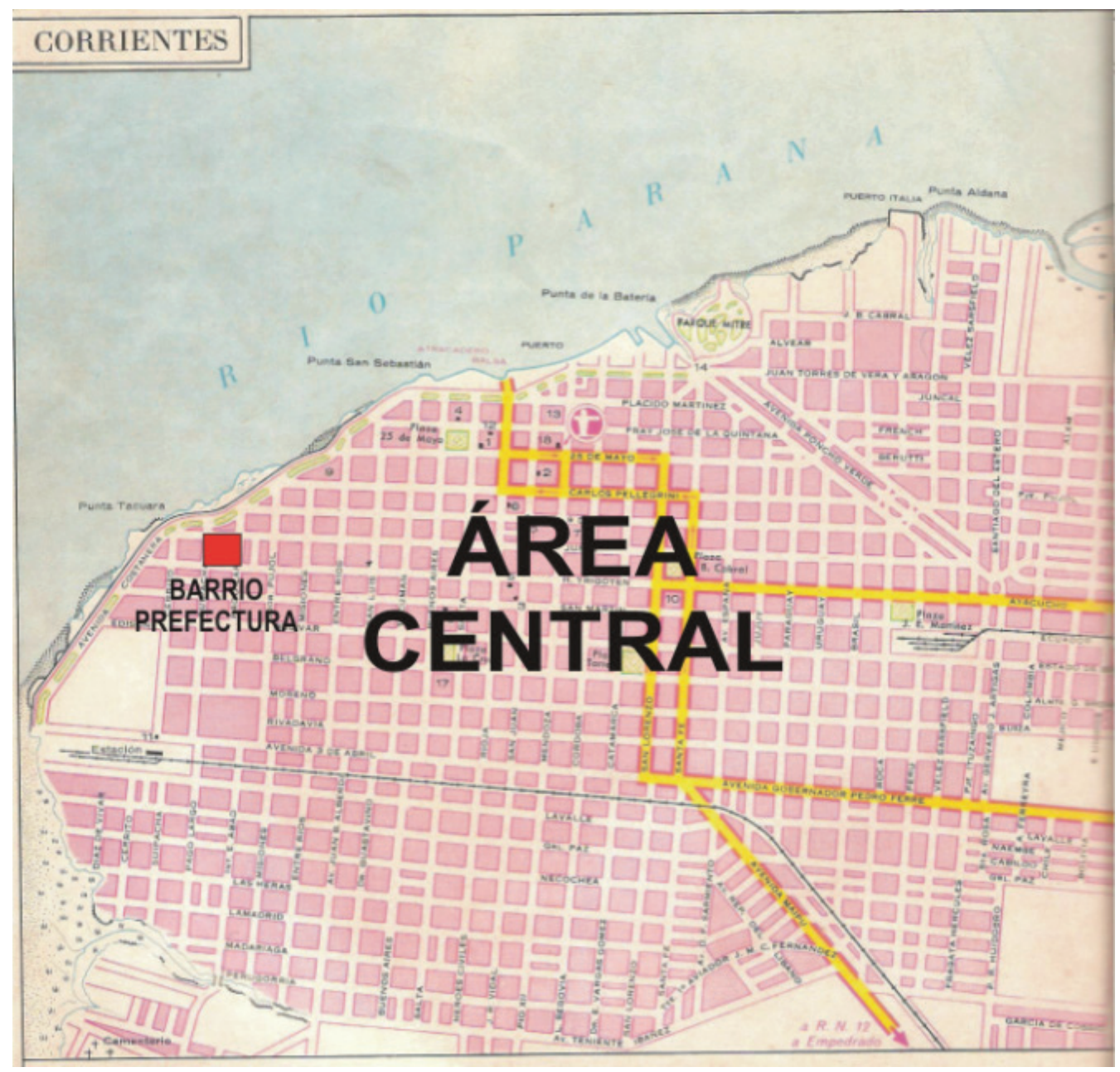

Fuente: Colección del autor. 
Figura 2. Imagen satelital del barrio en estudio

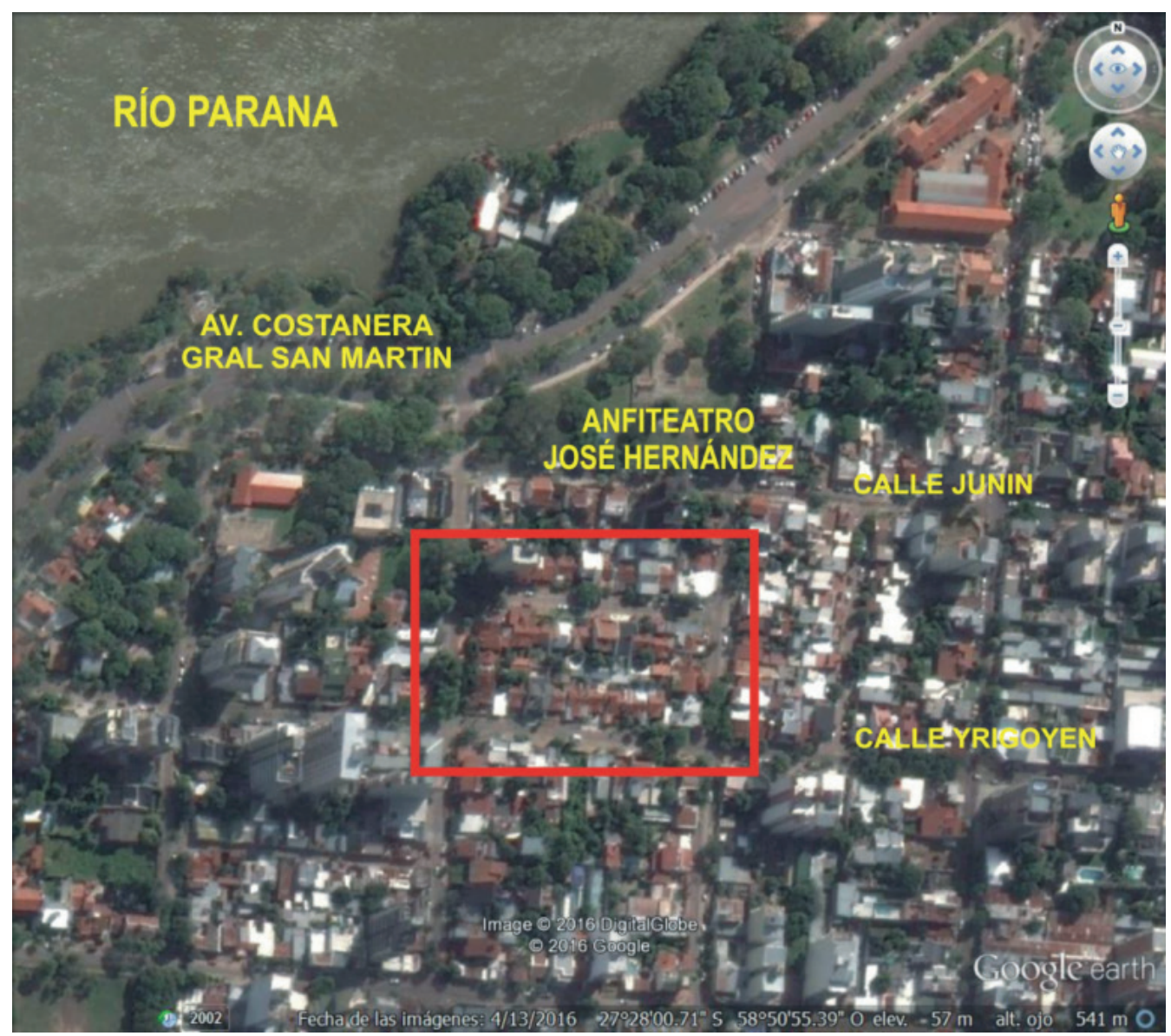

Fuente: Elaboración propia sobre Google Earth. 
Riera. Memoria vecinal y construcción barrial. El caso del barrio "Prefectura" de la ciudad de Corrientes.

Figura 3: Imagen externa inicial de las viviendas del barrio "Prefectura"

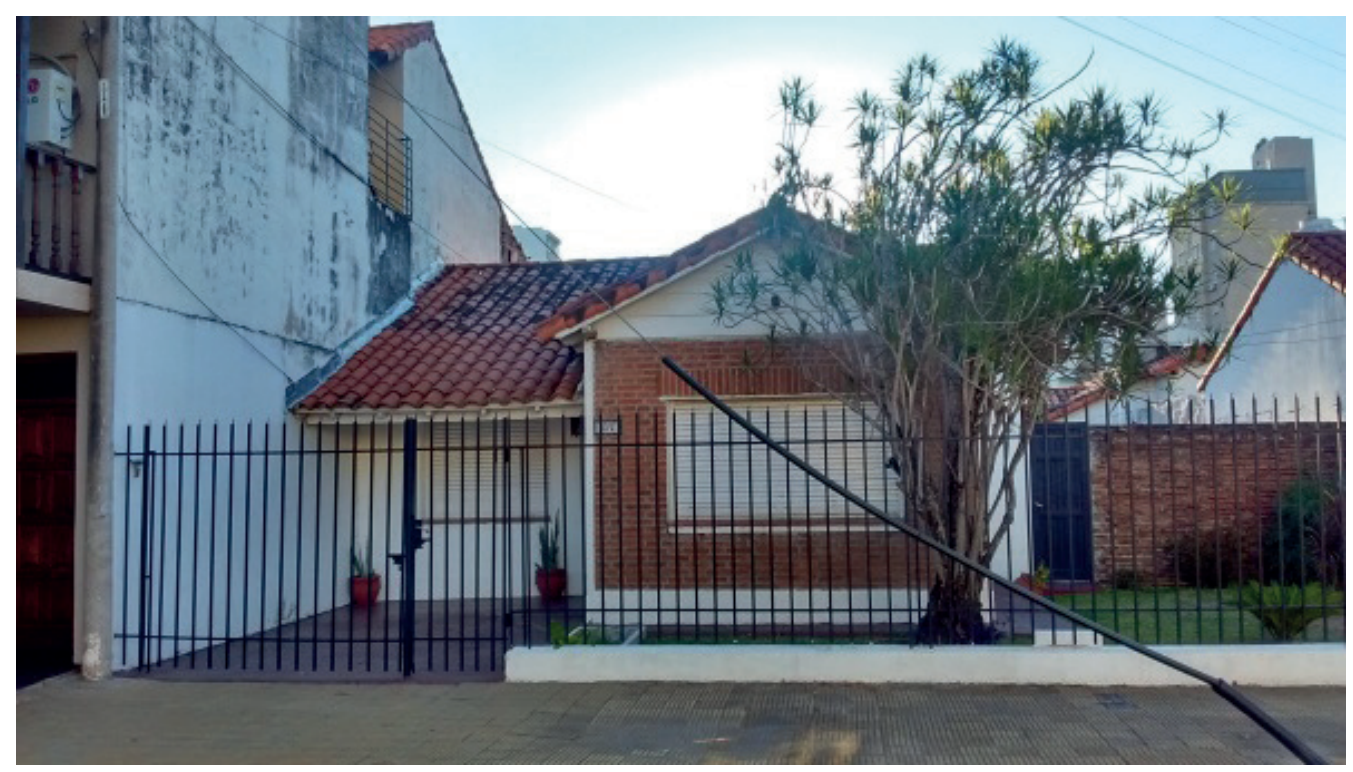

Fuente: colección del autor.

Figura 4. Imagen externa inicial de las viviendas del barrio "Prefectura"

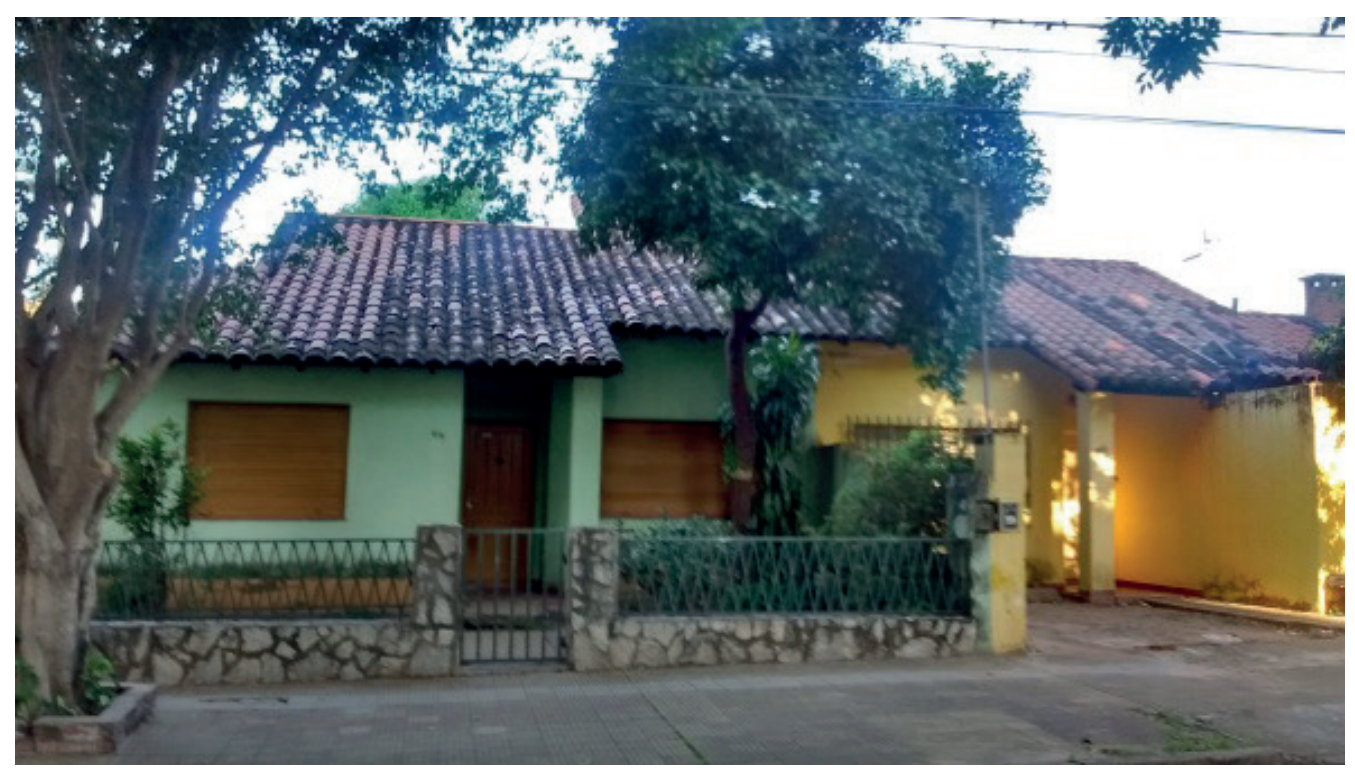

Fuente: Colección del autor. 
Figura 5. La transformación del entorno inmediato como la de alguna de las viviendas, se hace evidente al presente

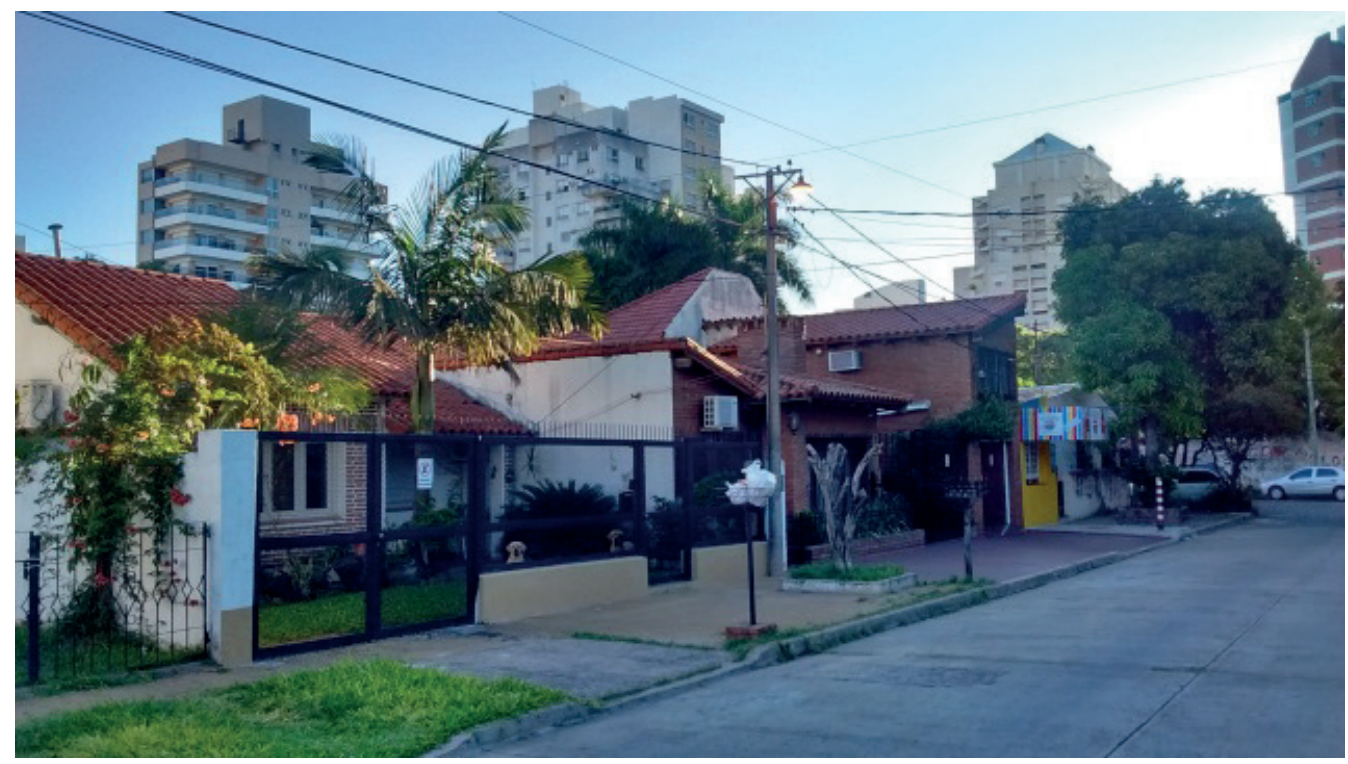

Fuente: Colección del autor.

Figura 6. La transformación del entorno inmediato como la de alguna de las viviendas, se hace evidente al presente

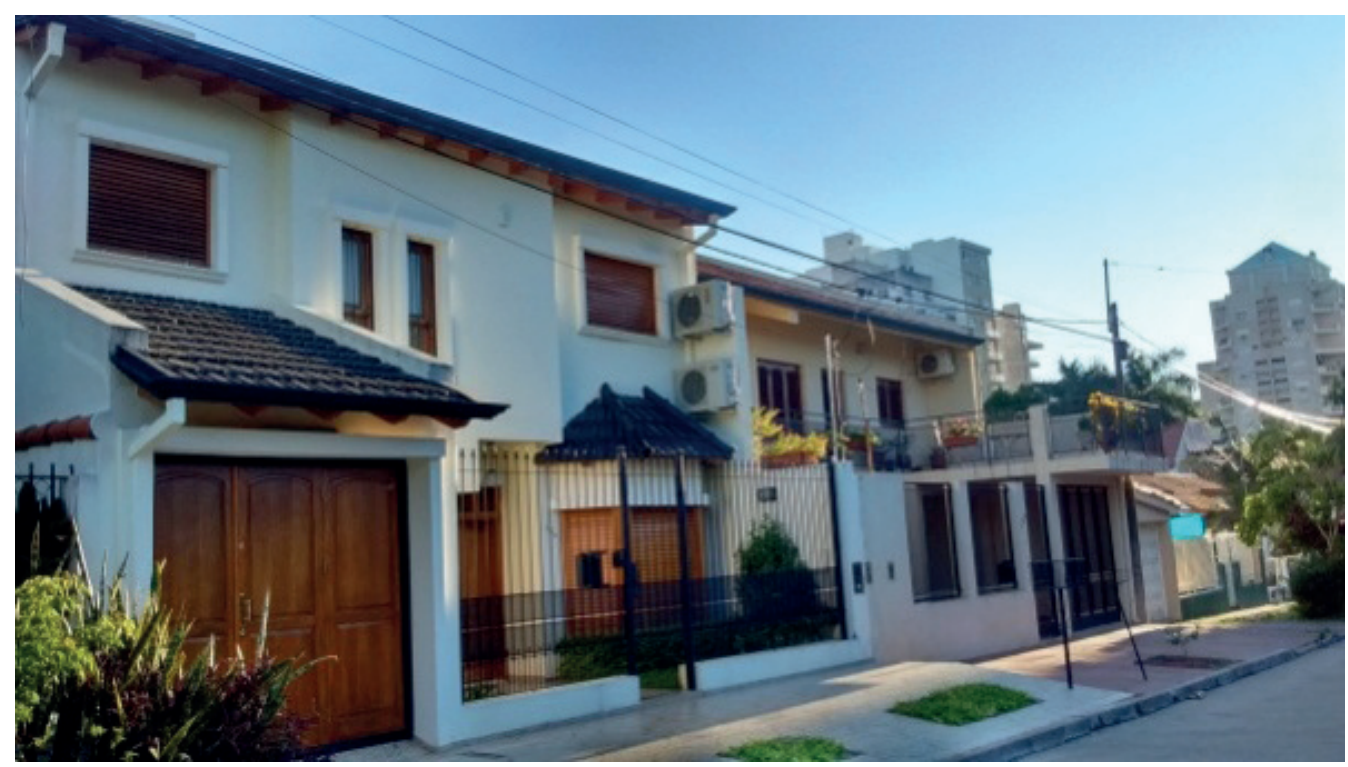

Fuente: Colección del autor. 
